its supra-internal and one hair on the infra-internal margin. Article III is longer than broad. The hypostome is strongly spatulate and possesses $3 / 3$ rows of teeth with six strong teeth in each row in the anterior half, and these are followed by $2 / 2$ rows of seven scale-like teeth.

Distribution and hosts. The species has so far been recorded from Borneo, Java, Sumatra, Burma, and new records show that the distribution of the species extends almost throughout India. It normally attacks only wild animals and hence is of little economic importance.

I wish to express my thanks to Doctor C. Strickland, Professor of Entomology at the Tropical School of Medicine, Calcutta, for identifying the specimen.

\title{
REFERENCE
}

Sharif, M.-Records of the Indian Museum, Vol. XXX, Part III, pp. 217-344.

\section{RED MULTIPLE MADDOX ROD WITH A PRISM*}

BY

Conrad Berens, M.D.

NEW YORK, N.Y.

AFTER considerable difficulty had been experienced in obtaining a Maddox rod without an undesirable prism of varying strength, the advantage of incorporating a prism of known strength in the Maddox rod became apparent and the rod to be described was constructed. $\dagger$

The literature from 1890 (the time when Maddox ${ }^{1}$ first presented this important diagnostic instrument) to the present apparently contains no reference to the intentional incorporation of a prism in the rod + or the routine use of a weak prism with the rod although its optical defects have been noted, ${ }^{2}$ and ingenious adaptations have been suggested.3, 4

One of the cleverest adaptations is that of Ballantyne ${ }^{5}$ who modified the Maddox rod so that the vertical and horizontal deviation could be determined simultaneously and the axis of the single prism indicated without the use of formulae or prismometric scales, which will correct the combined deviation.

\footnotetext{
* Presented before the American Ophthalmological Society, June 5, 6, 7, 1935. Hot Springs, Virginia.

† Made by E. B. Meyrowitz Company, New York, N.Y.

$\ddagger$ This statement was confirmed by Miss Maddox. ${ }^{6}$
} 
Description of the Maddox Rod and Prism.-A red multiple Maddox rod was constructed, with a $0.75 \Delta$ prism with the base at right angles to the rod image. Two sizes were ordered, one to be inserted into the trial frame of usual size (Fig. A), the other to be used with the Bausch and Lomb Ophthalmic Test Lenses (Fig. B). A short handle, in line with the streak image, attached to the frame, facilitates rapid rotation of the device and

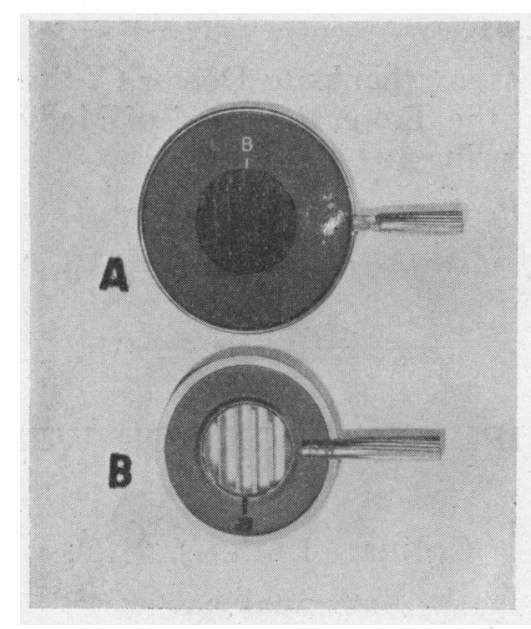

A red multiple Maddox rod with a $0.75 \Delta$ prism. (A) for insertion into a trial frame for lenses of the usual size; (B) for use with the Bausch and Lomb Ophthalmic Test Lenses.

reversal of the position of the base of the prism. Colourless multiple rods also are obtainable with the $0.75 \Delta$ prism incorporated.

Method of using this Maddox Rod and Prism.-In the examination of a person with no vertical imbalance of the ocular muscles, quickly rotating the prism will cause the line to appear alternately above and below the light at approximately equal distances. With the rod held over the right eye and the prism base up, if the red streak of light is observed to be exactly through the centre of the light, the patient has $0.75^{\Delta}$ of left hyperphoria. This test enables the examiner to make rapid measurements and to eliminate vertical errors which are less than $0.75 \Delta$.

Advantages of the Combined Maddox Rod and Prism.-The rod is especially useful in the study of small vertical deviations, and in quickly eliminating low degrees of lateral imbalance. It is well adapted for the examination of applicants for the Air services of the Army and Navy because negligible amounts of heterophoria 
may be quickly and easily eliminated. Simulation may be studied rapidly without the introduction of other prisms of questionable strength.

\title{
REFERENCES
}

1. Maddox, E. E.-The Rod Test in Ocular Pareses and Paralyses. Ophthal. $R e v .$, p. 287, 1890.

2. Dolman, P.-Maddox Multiple Red Rod, Consideration of Some of Its Optical Defects. Arch. of Ophthal., Vol. XLIX, p. 194, 1920.

3. Schild, E. H.-Determination of Heterophoria. Ophthal. Rec., June, 1905.

4. Wray, C.-Cyclophorometer. Trans. Ophthal. Soc. U.K., Vol. XXXII, p. 163, 1912.

5. Ballantyne, A. J.-The Simultaneous Correction of Horizontal and Vertical Deviation, Facilitated by a Slight Modification of the Maddox Rod, Ophthal. Rev., Vol. XXXIII, p, 165, 1914.

6. Yates Mrs. (Mary Maddox).-Personal Communication, May 31, 1935.

\section{PHOSPHOLIPID CONTENT OF CATARACTOUS HUMAN LENSES*}

\author{
BY \\ P. W. Salit, M.D. \\ IOWA CITY
}

Litrle quantitative work has been done on the phospholipid content of crystalline lenses, especially those which are cataractous. Several reports of qualitative nature, however, have been published on myelin-like or birefractive substances in cataractous lenses. + Mettenheimer (185i) was the first to describe birefractive substances, regarded as myelin, in cataractous lenses; these were not found in normal lenses. Laptschinsky (1876) made the first quantitative estimation of lecithin in normal ox lenses and found it to constitute 0.23 per cent. of the dry weight, however the ages of the animals and method of analysis were not published. Cahn (1881) carried out a quantitative estimation of lecithin in both normal and cataractous human lenses; the former contained 0.63 and the latter 0.80-4.52 per cent. of the dry weight. But he, like his predecessors, neglected the age factor. Furthermore, no differentiation between lenses extracted by the intra- and extra-capsular methods was made. By the first method one obtains the entire lens, and by the second only the nucleus and a small amount of cortex. In later investigations all lipids, for which the lenses have been analyzed, were found to increase in both normal and cataractous lenses with advancing age; they have been found

\footnotetext{
- From the Department of Ophthalmology, State University of Iowa, U.S.A.

+ For a detailed discussion of myelins and birefractive substances found in cataractous lenses see Krause (1932, 1934, 1935).
} 